\title{
A mixed treatment comparison of Erlotinib vs. placebo and Erlotinib vs. Geftinib using Bayesian approaches
}

\author{
Iftekhar Khan*, Gianluca Baio, Saira Ahmed \\ From 2nd Clinical Trials Methodology Conference: Methodology Matters \\ Edinburgh, UK. 18-19 November 2013
}

\section{Background}

Erlotinib and Gefitinib have proven efficacy in patients with non small cell lung cancer (NSCLC). However, evidence for a direct comparison between the two treatments does not exist. We conducted a mixed treatments comparison (MTC), so that an indirect comparison of Erlotinib vs. Gefitinib can be made and a formal economic evaluation can be consequently undertaken.

\section{Methods}

Evidence was synthesized from published randomised controlled phase III trials, including recent evidence for Erlotinib from a trial sponsored by the CRUK \& UCL Cancer Trials Centre comparing Erlotinib with Placebo. The effects of Erlotinib and Gefitinib on overall survival (OS) and progression-free survival (PFS) were compared using a MTC method with Placebo as the common comparator. A Bayesian approach was used to carry out the MTC. A further economic evaluation was undertaken under a Bayesian framework.

\section{Results}

Seven randomised controlled trials were included. Both interventions offered improvements in OS and PFS compared with placebo. Using MTC analysis, the OS hazard ratio (HR) for Erlotinib vs. Placebo was 0.83; $95 \%$ credible interval $(\mathrm{CI})$ of $(0.31,2.38)$; for PFS $\mathrm{HR}=0.81$; $95 \%$ CI $(0.12,5.65)$; for Gefitinib vs Placebo: OS HR=0.86; $95 \%$ CI $(0.27,2.54)$; PFS HR was 0.42; 95\% CI $(0.06,2.79)$; OS HR for Erlotinib vs Gefitinib was 0.98 ; $95 \%$ CI $(0.24,4.58)$ and for PFS was $1.84 ; 95 \%$ CI $(0.14,31.2)$.

University College London, London, UK

\section{Conclusion}

Both Erlotinib and Geftinib show improved OS and PFS over Placebo on average. However, although Erlotinib and Gefitinib appear equivalent in terms of OS, Gefitinib appears to offer improved PFS. This is likely to improve HRQoL prior to progression and have an important impact on the cost per Quality Adjusted Life Year (QALY).

Published: 29 November 2013

doi:10.1186/1745-6215-14-S1-P119

Cite this article as: Khan et al:: A mixed treatment comparison of Erlotinib vs. placebo and Erlotinib vs. Geftinib using Bayesian approaches. Trials 2013 14(Suppl 1):P119.

\section{Submit your next manuscript to BioMed Central and take full advantage of: \\ - Convenient online submission \\ - Thorough peer review \\ - No space constraints or color figure charges \\ - Immediate publication on acceptance \\ - Inclusion in PubMed, CAS, Scopus and Google Scholar \\ - Research which is freely available for redistribution

